\title{
Recent Trends in Prediction of Earthquake
}

\author{
Kaushik K. Ghosh \\ Assistant Professor, Department of Geology \\ Jogamaya Devi College, Kolkata \\ kaushikkghosh@yahoo.co.uk
}

\begin{abstract}
Earthquake is becoming a common natural hazard in Indian subcontinent, especially in extra-peninsular Himalayan region. It has a tremendous destructive power which strikes the earth's surface suddenly and sometimes unpredictably. In the present discussion, a generalised idea along with the development of recent state-of-the-art technology related to the prediction of earthquake has been considered. Mitigating earthquake covers from the monitoring of active fault and monitoring of precursory activities like radon discharge from microcracks; electromagnetic emissions; water level and temperature changes; ground uplift and tilt; changes in ionospheric parameters etc to the unusual behaviour of animals. A grand success is achieved in the long-term prediction of earthquake. However, short term prediction is yet to be attained.
\end{abstract}

Keywords: Natural disaster, earthquake, long-term prediction, short-term prediction, tsunami

\section{Introduction}

Earthquakes have a tremendous destructive power; they strike quickly, and many, many times unexpectedly. Within seconds or minutes thousands of people can die, and buildings turn into piles of debris. Most earthquakes occur at the boundaries of tectonic plates, or active faults. An earthquake can destroy any man made structure (buildings, bridges, roads, etc) in several ways: (i) by ground shaking; (ii) by aftershocks and fire and (iii) by tsunamis. Ground shaking is caused by the surface waves formed during an earthquake. Most buildings can withstand up and down shaking, but few will resist side to side vibration. Buildings that are built on solid rock have better chances to remain intact than buildings that are built on soft rocks. Soft rocks or loose soil can temporarily take some of the properties of a liquid during an earthquake. This is called liquefaction. Most earthquakes are followed by a series of smaller ones, originating close to the focus of the large earthquake. These smaller earthquakes are called aftershocks. Although the magnitude of these aftershocks is considerably smaller than the initial earthquake, many stillstanding but weakened buildings might collapse during the aftershocks.

In the modern urban settlement, most of the domestic supply system, may it be pipe lines of water, or gas or heavy wiring of electrical supply, run under the ground. The ground movement ruptures the gas lines, and a spark form the short circuit of underground electrical wiring is enough to start a devastating fire. After the 1906 San Francisco earthquake the fires destroyed about 3000 buildings and burned about 11 squares $\mathrm{Km}$ of the city.

Tsunamis are huge ocean waves created by displacement of water due to underwater landslide or volcanic eruption and due to the slippage of the boundary between two adjacent lithospheric plates. But main cause of tsunami is caused by the displacement of water during an underwater earthquake. They cause damage along coastlines. Tsunamis can travel up to $900 \mathrm{~km} /$ hour at the deepest point of the water, but slow down as they get near the shore, eventually hitting the shore at 50 to $60 \mathrm{~km} / \mathrm{h}$. The energy of the wave's speed is transferred to height and sheer force as it approaches the shore.

\section{Earthquake - A Natural Disaster}

Natural Disasters are catastrophic events that are extreme and usually sudden. Natural events like Earthquakes, Tsunamis and Volcanic eruptions are inevitable. What makes these events more dangerous and disastrous is not that these events are inevitable but that these are still unpredictable. Therefore it is one of the major challenges felt presently by the scientific community world over to find a reliable seismic precursor. The researchers have started investigation in this direction a couple of decades ago. The studies carried out in the past using traditional seismological methods [1] have solved the problem of long term prediction to a much extent. However the problem of short term prediction remains yet unsolved. Although the field of short term prediction is in its initial stages of study, yet precursors recorded for certain earthquakes indicate that there is reason enough to believe that precursors do exist and can be observed for forecasting earthquakes. In case of an earthquake, certain precursory activity can be expected, if the observation is made in the near vicinity of causative rupture. These precursory activities may include radon and helium emanation; electromagnetic emissions; water level and temperature changes; ground uplift and tilt; Changes in ionospheric parameters and so on.

Generally, earthquake researches are considered in four different ways:

A.Analyzing seismograms generated by earthquakes

B.Studying frictional properties of various types of rock in the laboratory or in the field

C.Measuring the slow accumulation of strain between earthquakes with survey techniques

D.Large-scale dynamic models of earthquakes and tectonics.

Again, variations in the gravity field can also be considered as a predictor of seismic behaviour.

To be most effective, an earthquake prediction must correctly forecast three things: (i) where an earthquake will occur (ii) when it will occur and (iii) what magnitude will it be. For 


\section{International Journal of Science and Research (IJSR) \\ ISSN (Online): 2319-7064}

Index Copernicus Value (2013): 6.14 | Impact Factor (2015): 6.391

that, evidence must be integrated from a variety of sources, including: geological evidence, statistical information, seismic measurements, physical measurements and other information.

Geological Evidence: From the knowledge of the geology, and geological processes, in an area, combined with previous earthquake records, we can prepare earthquake hazard maps. Here the geological past history is a guide to the future. The information of good earthquake map should include (i) the geology of the area including landslides, ground settling; (ii) water-logged and poorly consolidated rocks; (iii) location of active and inactive faults and their types; (iv) evidence for recent fault movement; the earthquake history of the area; (v) location of previous earthquake epicentres; (vi) determination of previous earthquake intensities and (vi) correlation of earthquakes with local faults.

Statistical information is of different types: Different probabilistic models are generally adopted for the prediction of earthquake. It has long been established that earthquakes are largely clustered on plate boundaries, but there remains much debate over earthquake recurrence times. However, there is a rough relationship between the magnitude of an earthquake and the length of the fault that ruptures. Similarly the recurrence time of an earthquake can be predictably calculated from the statistical method. The recurrence interval of Parkfield earthquake region, located on a 15 mile segment of the San Andreas Fault, is calculated as 22 years by the United States Geological Survey [3]. In a similar manner, evidence for fossil earthquakes along the southern segment of the San Andreas fault near Los Angeles shows that major earthquakes occur here roughly every 160 years.

The basic principle between calculating recurrence interval is explained by the 'Seismic Gap Theory'. If earth movements that ultimately lead to earthquakes are steady and constant, then active regions that have been seismically quiet or inactive for some time are probably building up excessive elastic strain. This could mean that these regions are potential locations for future earthquakes. The longer the time interval without seismic activity, the more elastic strain is being built up and therefore the larger the subsequent earthquake. This theory has been applied to segments of individual faults and also to the broader regions along subduction zones.

A corollary to the seismic gap theory is that faults that are constantly moving (creeping), or experience frequent earthquakes, are not going to build up large amounts of elastic strain. Consequently, these fault segments are unlikely to produce large earthquakes. For example, at Parkfield for example, there are earthquakes about every 22 years and their magnitudes have been relatively small $(5.5-6.0)$.

Intense observation on the foreshocks and aftershocks of an immediate earthquake is important for a short-term prediction. In some cases, a large earthquake is preceded by a series of smaller quakes ( $\mathrm{M}=3-5$ in Richter Scale) which are called foreshocks. Foreshocks may occur from months to days before a big earthquake. In general, the longer the period of foreshocks the larger the ensuing earthquake. The problem is to identify foreshocks from lowlevel, random earthquake activity which is common in earthquake prone areas. Sometimes, there may be no preceding foreshock before the main shock. The method has been used with success some times, but has also produced "false alarms". Similarly, after a large earthquake, the crust around the active fault is heavily disturbed and very unstable. Consequently, movement and readjustment take place leading to more earthquakes. These earthquakes, called aftershocks, are usually smaller in magnitude $(\mathrm{M}=3-5)$ than the main earthquake. With time, both the frequency and intensity of these earthquakes decrease. Despite their smaller magnitude, they are not without hazard. Buildings damaged or weakened by the main earthquake can collapse as a consequence of aftershocks. It may cause further damage to the new establishment created by the people who have already returned home.

Physical measurement and close monitoring of active fault may help us to find out and mitigate earthquake. In order to monitor movement along faults and the build-up of elastic strain due to the movement, the basic principle is to measure changes in distance between two nearby points on the opposite blocks of fault, ground elevation, or the change of physical properties of a rock. Several types of geophysical measurement are possible, including: (i) Geodetic survey (measurement of the change in distance between two points across the fault using a laser beam.); (ii) tilt (change in slope measured by tiltmeter and creepmeter) and (iii) electrical conductivity surrounding the active fault.

Other effective but controversial methods are (i) unusual behaviour of animals; (ii) changes in the level and quantity of groundwater; (iii) increase in the release of radon gas.

Radon is continuously produced in rocks by the decay of radioactive minerals. If the rock is suddenly fractured due to the build-up of strain - then the accumulated radon will be released and dissolved in groundwater. Thus the sudden increase in radon abundances in streams, wells and groundwater might be a useful method for predicting earthquakes. But the main problem is: we do not have enough information on the background levels of radon in streams, wells etc.

\section{Conclusion}

Therefore, a long-term prediction can be made by identifying seismic gaps tied with the measurement along the active fault. However, short-term prediction, like weather forecasting, is not yet possible due to lack of adequate knowledge and absence of a time-tested real-time earthquake model.

\section{Other Recommendations}

The author thanks Ms. Keya Bandyopadhyay of Jogamaya Devi College for her constant support and continual encouragement. 


\section{References}

[1] Gokhberg M.B., Morgounov V.A and Pokhotelov O.A., (1995) "Earthquake prediction: Seism electromagnetic phenomena", Reading Philadelphia, Gordon and Breach Science Publishers, pp 287.

[2] Pacific Tsunami Warning Center - < http://ptwc.weather.gov/ >

[3] U.S. Geological Survey - <www.usgs.gov>.

\section{Author Profile}

Kaushik K Ghosh received M.Sc. degree from the University of Calcutta, Kolkata and has submitted for Ph.D. degree from the same university. He is presently working as an Assistant Professor of Jogamaya Devi College, Kolkata. His research interest includes banded iron formation (BIF) and related iron ore deposits of India. He has published several papers in national and international journals. 